\title{
The role of nonneuronal neurotrophins in the brain Marija Čarman-Kržan
}

Address: Department of Pharmacology and Experimental Toxicology, Faculty of Medicine, University of Ljubljana, 1000 Ljubljana, Slovenia

Email: Marija Čarman-Kržan - marija.carman-krzan@mf.uni-lj.si

from I5th Scientific Symposium of the Austrian Pharmacological Society (APHAR) Joint meeting with the Hungarian Society of Experimental and Clinical Pharmacology (MFT) and the Slovenian Pharmacological Society (SDF)

Graz, Austria. 19-21 November 2009

Published: 12 November 2009

BMC Pharmacology 2009, 9(Suppl 2):A59 doi:I0.II86/I47|-22I0-9-S2-A59

This abstract is available from: http://www.biomedcentral.com/I47I-22I0/9/S2/A59

(c) 2009 Čarman-Kržan; licensee BioMed Central Ltd.

\section{Background}

Neurotrophins (nerve growth factor, NGF; brain-derived neurotrophic factor, BDNF; neurotrophin-3, NT-3) are involved in various CNS functions from differentiation and neuron survival to synaptogenesis and synaptic plasticity. They are synthesized in neurons and also in nonenuronal cells (astrocytes), which therefore represent an important local source of trophic support in normal and diseased bran. Their synthesis in astrocytes is susceptible to up-regulation by cytokines, hormones, drugs and synaptically released neurotransmitters. They all show significant but diverse regulatory effects on neurotrophin levels in astrocytes with differences in dose-dependency and short-term kinetics. Cytokines are the most effective stimulators of NGF synthesis and/or secretion, whereas the monoaminergic neurotransmitters noradrenaline, adrenalin, 5-HT, dopamine and histamine differentially affect synthesis of all three neurotrophins. Their stimulatory effect is a specific receptor-mediated process involving either cytokine (IL- 1$)$, adrenergic $\left(\alpha_{1}, \beta_{1} / \beta_{2}\right)$, dopaminergic $\left(\mathrm{D}_{1}\right)$ or histamine $\left(\mathrm{H}_{1}, \mathrm{H}_{2}, \mathrm{H}_{3}\right)$ receptors and corresponding intracellular mechanisms.

\section{Summary}

In conclusion, the studies on the mechanisms of astrocytic neurotrophin regulation suggest the importance of positive cooperation between the excitatory monoaminergic neuronal activity and astrocytic neurotrophic support (neuron-astrocyte crosstalk) in the developing, mature and diseased brain. 